\title{
ESCLARECIMENTO E EDUCAÇÃO EM KANT: A AUTONOMIA COMO PROJETO DE MELHORAMENTO HUMANO
}

\author{
José Edmar Lima Filho
}

\begin{abstract}
Resumo: A presente exposição propõe a tese, com base no pensamento de Immanuel Kant (17241804), de que educação e melhoramento humano são noções que se implicam necessariamente. Isso significa que não se pode conceber, desde a posição kantiana, uma proposta pedagógica cujo cume não desemboque na construção de si do sujeito como instância racional teórico-prática. Parte-se, pela leitura imanente da opera kantiana, da necessidade da admissão da unidade da razão, para se desdobrarem os argumentos que pretendem justificar a posição da pedagogia como o cumprimento do ideal de Esclarecimento moderno, o qual articula em seu bojo o desenvolvimento do indivíduo, seja do ponto de vista teórico-especulativo, seja daquele moral. Ao fim e ao cabo, a proposta da educação coincide com a proposta do Esclarecimento, que, por sua vez, nada mais é que aquela da autoconstrução do sujeito como senhor de si mesmo, como horizonte aberto em permanente aprimoramento.
\end{abstract}

Palavras-Chave: Educação. Formação humana. Esclarecimento.

\section{O PROBlema do EsClareCIMENTO ENTRE O UNIVERSO TEÓRICO E O PRÁTICO}

O escrito de 1784, "Resposta à pergunta: o que é Esclarecimento"? (“Beantwortung der Frage: Was ist Aufklärung?"), talvez seja um dos mais conhecidos entre aqueles de Immanuel Kant. Curto, recheado de afirmaçóes célebres, de leitura mais "corrida" e "sem maiores problemas", é um texto que "destoa", em certo sentido, de composiçóes kantianas mais "duras", como a Crítica da razão pura [Kritik der reinen Vernunft (1781/1787)]. Entretanto, por trás dessa aparente "facilidade", se esconde uma proposta densa e séria que

\footnotetext{
${ }^{1}$ Professor Adjunto do Curso de Filosofia da Universidade Estadual Vale do Acaraú (UVA), Sobral, CE - Brasil. (D) https://orcid.org/0000-0003-2564-2651 E-mail: semedmar@yahoo.com.br

Doutor em Filosofia pela Universidade Federal do Ceará. Líder do Grupo de Pesquisas Ludwig Feuerbach e pensamento pós-hegeliano (GPELF/UVA-CNPq), membro pesquisador do Grupo de Pesquisa em Filosofia da Religiāo (GEPHIR/UVA-CNPq) e do Laboratório de Estudos Hegelianos (LEH/ UVA-FUNCAP).
}

http://dx.doi.org/10.1590/0101-3173.2019.v42n2.04.p59

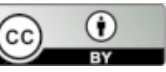

This is an open-access article distributed under the terms of the Creative Commons Attribution License. 
pode ser resumida na sentença "como tornar o indivíduo senhor de si mesmo?", a qual corresponde à pergunta "como fazer o homem capaz de superar o estágio de uma vida inautêntica ou, o que é o mesmo, inumana?” Se é assim, embora a questão se apresente claramente naquele texto, não é aí finalizada, em razão da retomada do tema em várias outras obras de Kant.

A resposta às questôes que levantei pode ser iniciada de muitos lugares; prefiro começar "do começo" ${ }^{2}$ da datação do texto, a saber, da publicação de dezembro de 1784 da Berlinische Monatsschrift. A justificativa para a escolha "desse começo" e não de outro vem desdobrada, a seguir, em dois argumentos complementares, quais sejam:

(i) Até 1784, Kant já havia escrito muita coisa, entre as quais sua "primeira” (?) grande obra, a Crítica de 1781, precedida, em 1770, pela Dissertatio sobre a forma e os princípios do mundo sensível e do inteligível, a partir das quais procura deixar claro, na proposiçáo de uma resposta aos problemas da (im)possibilidade da cientificidade da metafísica e de sua revolução metodológica, quais os poderes disponíveis à razão humana, do ponto de vista especulativo. A razão, enquanto critica a si mesma, pretende conceder as provas de suas potencialidades cognoscitivas, ao tempo em que, "ciente" de si, possui as ferramentas para fugir da ilusão de saber o que não sabe e apegar-se ao saber que lhe está disponivel. Assim, a razão, ao saber que sabe, também sabe que há um limite para o saber; sabe que náo sabe tudo e que este náo saber não significa necessariamente a inexistência do náo sabido, mas uma privaçáo cognoscitiva imposta por sua própria estrutura interna, algo que acaba lhe impondo a necessidade de fundamentar um outro domínio de atuaçáo que não aquele teórico.

(ii) No autoexame da razão da primeira Crítica, Kant também chegou, portanto, a outra conclusão importante, isto é, aquela de que o saber não é capaz de açambarcar todo o potencial da razão humana. Dito de outro modo: o poder de saber náo esgota a racionalidade, no sentido de que a razão, resguardados os direitos cognoscitivos de que dispóe, possui ainda outra capacidade, à qual Kant concederá coincidir com sua potência de dirigir a vontade com base em princípios. Isso significa que a razão humana, além do poder de saber, também possui o poder de orientar a ação, algo que permite o trânsito do problema epistemológico para o moral. Claro que aqui essa passagem está muito simplificada e rápida - posto que seria um tema para discussão, só ele; entre-

${ }^{2}$ Claro que aqui se assume o ônus de iniciar por algum lugar com o qual me comprometo, o que de per $s i$ já traz muitas questōes... seria, afinal, possível começar algo sem esse compromisso de base? 
tanto, o que interessa no momento é a conclusão a que Kant chegou, depois de avaliar, na dialética transcendental (transscendentale Dialektik), os problemas em que cai a razão humana, ao tentar aplicar as categorias do entendimento àquilo que não é empírico, como à liberdade, por exemplo [cf. a exposição sobre a terceira antinomia (Dritte Antinomie)]: não podemos saber, do ponto de vista teórico, o que seja a liberdade, pois isso é interditado pela nossa condição racional; mas a questão da liberdade continua nos interpelando, assim como outras, tais como aquelas de Deus, do mundo ou da alma - que são precisamente as questóes próprias da metafísica. Por que há essa tendência da razão para questóes que não pode responder ? $^{3}$ Diz Kant: se nossa razão for arquitetonicamente organizada, como um todo sistemático - e ele assume que sim -, as questóes da metafísica não podem ser simplesmente abandonadas; elas precisam ser tratadas, senão como objeto de saber, como princípios ou máximas lógicas das quais se serve a razão, como ponto de apoio a partir dos quais o homem pode saber algo. Assim, essas questóes - a que Kant chamará de ideias - dão a prova de que há outro uso possível da razão: elas nos concedem a possibilidade de abrir a reflexáo para um uso prático da razáo; numa palavra: para a moral. Daí que "o fim último da natureza sábia e providente na constituição da nossa razão, consiste somente no que é moral" [KrV A801, B829 (p. 636)].

Infelizmente (ou felizmente?), Kant não concluiu ali, na primeira Crítica, suas reflexôes sobre o universo prático. Elas foram abertas, embora não finalizadas lá - assim como o tema do Esclarecimento exposto acima -, o que justifica a existência de outras tentativas de embasamento da filosofia moral em textos ulteriores, a partir, sobretudo, da Fundamentaçáo da metafísica dos costumes [Grundlegung zur Metaphysik der Sitten (1785)].

Observando criteriosamente os argumentos anteriores, assim como os anos de publicação das obras mencionadas, tem-se, portanto, o texto WA em uma espécie de "via intermédia" entre a primeira edição da KrV e a GMS, o

\footnotetext{
${ }^{3}$ Conforme anuncia a primeira Crítica, "a razão humana [...] possui o singular destino de se ver atormentada por questôes, que não pode evitar, pois lhe são impostas pela sua natureza, mas às quais também náo pode dar resposta por ultrapassarem completamente as suas possibilidades" [ $\mathrm{KrV}$, A VII (p. 3) - sigo aqui a notação "canônica" utilizada para referir os textos de Kant, considerando a publicação original e a página estabelecida, por meio das abreviaturas propostas pela Kant-Forschungsstelle der Johannes Gutenberg-Universität Mainz, com a sigla AA (Akademie-Ausgabe), o número do volume, o número da página e a linha naquela edição. A exceção é quanto à Crítica da razão pura, citada pela abreviatura ordinária, seguida da indicação da paginação da primeira (A) e segunda (B) edição. Utilizo ainda, ao final de cada referência ao original, a paginação das ediçóes traduzidas das obras de Kant entre colchetes, que seguem indicadas na bibliografia.]
} 
que nos dá uma chave de leitura interessante: seria o problema do Esclarecimento resolvido apenas do ponto de vista epistemológico ou, antes, estaria vinculado igualmente ao problema moral?

O texto de 1784 dá pistas para elucidar a indagação, já quando é inaugurado pela afirmação de Kant: "Esclarecimento é a saida do homem de sua menoridade, da qual ele próprio é culpado." [WA AA VIII, 35:01-02 (p. 100)]. Operando analiticamente, temos alguns conceitos centrais nessa definição de Esclarecimento, quais sejam, os de (i) menoridade e (ii) culpa. Temos, entấo, que Kant aparentemente parte, em sua definição, de dois conceitos eminentemente utilizados no universo jurídico - que, obviamente, também podem ser considerados de uma perspectiva moral. O que interessa é que, a juízo de Kant, moral e direito são âmbitos próprios do universo prático, de modo que os conceitos em questão são mais pertinentes ao prático que ao teórico. O ponto é: se o problema do Esclarecimento for meramente epistemológico, qual a finalidade de defini-lo com base em conceitos práticos? Isso parece muito contraproducente para alguém, como Kant, cuidadoso do ponto de vista conceitual.

A questão fica ainda mais instigante: (i) a menoridade, por exemplo, tomada como conceito jurídico, pode (ainda que náo necessariamente) ser compreendida como um estágio de vida superado naturalmente. Seja-me permitido um exemplo anacrônico, quando ele pode ser didático: um indivíduo que hoje possui 17 anos, 11 meses e 29 dias, pela legislação brasileira, é considerado "menor de idade", condição que seria superada amanhã, quando de seu aniversário. Assim, passar da menoridade para a maioridade seria algo "automático", "natural”, e tornaria "absolutamente capaz" o indivíduo do ponto de vista da legislação brasileira - se não é afetado por qualquer condição orgânico-patológica, por exemplo, que o impossibilite de deliberar por si mesmo.

Quanto a (ii), temos que: o conceito de culpa está necessariamente atrelado ao de responsabilização que, por sua vez, pressupóe o de liberdade. Por isso, sem liberdade, não há moral nem direito, desde que se tenha em consideração que, para Kant, "prático é tudo aquilo que é possível pela liberdade" [KrV A800, B828 (p. 636)]. Ora, se alguém é culpado por algo, é porque pode ser responsabilizado por isso. No entanto, quem pode ser culpabilizado por não ter 18 anos completos e ser menor de idade, para voltar àquele exemplo? Quem poderia ser responsabilizado por ter nascido no ano em que nasceu e, por isso, estar na condição de menoridade jurídica? 
A proposta de Kant, ao contrário da hipótese alimentada provisoriamente, informa-nos (i) que a menoridade não é abandonada "automaticamente" e, mais, (ii) que o indivíduo pode ser culpabilizado por permanecer nela. Isso significa que o conceito de Esclarecimento, de que se serve Kant, está certamente fundamentado em premissas distintas: a menoridade não é superada "naturalmente", porque depende de dois elementos básicos, quais sejam, decisão (Entschließung) e coragem (Muthes); a falta deles enseja responsabilizar o indivíduo por estar na condição de menoridade, posto que lhe foi concedida a faculdade do entendimento. ${ }^{4}$

Parece haver aqui, portanto, uma pressuposição antropológica fundamental da parte de Kant: a de que o homem é naturalmente preguiçoso e covarde - não é demais lembrar que Kant insiste em afirmar, em textos posteriores, que a fundamentação da moral necessariamente não esteja dada por uma antropologia empírica. ${ }^{5}$ Isso justificaria por que, a seu juízo, "a preguiça e a covardia são as causas pelas quais uma tão grande parte dos homens [...] continuem no entanto de bom grado menores durante toda a vida. São também as causas que explicam por que é tão fácil que os outros se constituam em tutores deles." [WA AA VIII, 35:09-13 (p. 100)]. Algumas conclusóes importantes, derivadas deste trecho, merecem destaque: (i) a menoridade não é prerrogativa de um grupo pequeno de indivíduos, mas de uma "tão grande parte dos homens" - o que não é pouco!; (ii) a permanência na condição de menoridade não é considerada, pelos próprios menores, como algo negativo, mas como algo "positivo"; (iii) a prova de que a menoridade não é superada automaticamente é dada pela afirmação de que é possível ser menor "durante toda a vida" e, pior, ainda gostar disso; (iv) preguiça e covardia, ao mesmo tempo em que favorecem a menoridade - porque, da parte do menor, o fazem gostar de permanecer naquela condição - favorecem também a tutela de outros sobre eles.

Daí que a consequência a que Kant chega não poderia ser outra, senão a de que a menoridade é amparada pela "sensação" de "comodidade"/"conveniência"

\footnotetext{
${ }^{4} \mathrm{O}$ entendimento é apresentado na primeira Crítica como, propriamente, a faculdade capaz de elaborar juízos, o que significa que, se as ciências se fundam em juízos sintéticos a priori, estes só são possíveis pela açáo do entendimento com suas categorias, de modo que "as categorias permitem pôr a priori as leis gerais da natureza” (MORUJÃO, 2001, p. XV).

${ }^{5}$ Essa provocação pode ser tomada como elemento de justificação para o problema da educação como parte da "ética impura" ou da "segunda parte da Ética" de Kant [que a Ética tenha duas partes, uma "racional" e uma "empírica", é defesa posta em GMS, AA IV, 388:12-13 (p. 65)], na hipótese de que o tema do Esclarecimento mantenha relação com a questão da educação, como pretendo estabelecer; esta é igualmente a posição assumida por Louden (2000, p. 33ss).
} 
(Bequemlichkeit) [WA AA VIII, 35:13 (p. 100)], absolutamente avessa ao "esforço" (Bemühung); em suas palavras, "se tenho um livro que faz as vezes de meu entendimento, um diretor espiritual que por mim tem consciência, um médico que por mim decide a respeito de minha dieta etc., então não preciso de me esforçar eu mesmo" [WA AA VIII, 35:13-16 (p. 100; 102)]. O esforço por desvencilhar-se da condição de menoridade seria, nesse caso, análogo à superação de uma espécie de "condiçâo habitual" a que o menor estaria submetido, em razão da repetição cotidiana de atitudes "impensadas", "não reflexivas", no sentido de que fundadas no mero cumprimento de determinaçóes externas ao indivíduo, o que torna a menoridade nada mais que heteronomia. ${ }^{6}$ O conceito de heteronomia, no entanto, em oposição ao de autonomia, só seria desenvolvido de modo mais acurado quando da composiçáo posterior da GMS, obra em que Kant apresenta a heteronomia como uma espécie de determinação extrínseca da vontade subjetiva e causa, por isso, dos princípios ilegítimos da moralidade [GMS, AA IV, 441:01ss (p. 287ss)].

O menor é compreendido, portanto, como aquele que não é capaz de se autodeterminar, no sentido de que precisa de algo distinto de si como comandante de seu agir; por oposição, o esclarecido é o que empreendeu a saída da heteronomia e se dirigiu à autonomia ${ }^{7}$, apresentada na mesma Fundamentação como princípio supremo da moralidade [GMS, AA IV, 440:14ss (p. 285ss)]. Desse modo, não é mais possível dissociar o tema do Esclarecimento (Aufklärung) da problemática moral, o que significa que permanecer na me-

\footnotetext{
${ }^{6}$ É claro que se alguém age no sentido de levar a efeito uma tarefa $x$, certamente empreende certo esforço intelectual para lograr êxito na execuçáo da atividade, o que significa que a ação pressupôs reflexão. Não se trata, no texto de Kant, de dizer o inverso, senão de informar que essas açōes, quando realizadas por determinaçóes externas, em vez de internas, são derivadas de mandatos heterônomos e, portanto, são avessas à autonomia do sujeito agente.

7 É importante perceber, portanto, que a ideia do Esclarecimento (Aufklärung) está associada a certo caráter processual, dinâmico, conforme acentua Mainka, para quem o "Esclarecimento objetiva a uma mudança de estados no sentido de uma melhoria do não-esclarecido para esclarecido, de menos esclarecido para o mais esclarecido. Esclarecimento é processo de mudança. A partir de um certo ponto, o processo é realizado de maneira autônoma pelo próprio indivíduo. Porém, enquanto este estado de um certo Esclarecimento ainda não foi alcançado - 'falta ainda muito', o próprio Kant afirma, sem entre-

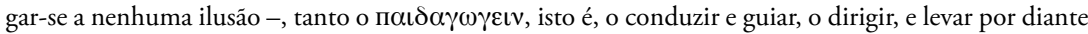
de crianças, de meninos e meninas, de filhos e filhas, enfim, a pedagogia adquiriu uma função central no processo de Esclarecimento. A 'época do Esclarecimento' era, por isso, não só uma 'época filosófica', mas sempre também, uma "época pedagógica”" (MAINKA, 2005, p. 168), tese que acaba por admitir a vinculação do tema do Esclarecimento ao da educação, na interpretação da teoria filosófica de Kant.
} 


\section{noridade é uma espécie de violência à própria razáo humana, destinada, a juízo de Kant, àquilo que é moral. ${ }^{8}$}

Algumas outras pistas podem ser convocadas, para dar a conhecer essa implicação entre Esclarecimento e moral, uma das quais se encontra na Doutrina da virtude (Tugendlehre), da Metafísica dos costumes [Die Metaphysik der Sitten (1797)], quando Kant afirma:

1. Um ser humano tem o dever de erguer-se da tosca condição de sua natureza, de sua animalidade (quoad actum) cada vez mais rumo à humanidade, pelo que somente ele é capaz de estabelecer ele mesmo fins; tem o dever de reduzir sua ignorância através da instruçáo e corrigir seus erros. E não é meramente que a razão tecnicamente prática o aconselha a fazê-lo como um meio para seus outros propósitos (ou arte); moralmente a razáo prática o comanda absolutamente e faz desse fim o dever dele, de modo que possa ser digno da humanidade que dentro dele reside. 2. Um ser humano tem o dever de conduzir o cultivo de sua vontade à mais pura disposiçáo virtuosa, na qual a lei se converte também no incentivo para suas ações que se conformam ao dever e ele acata a lei a partir do dever. Essa disposição é perfeição interior moralmente prática. Uma vez que é um sentimento do efeito que a vontade legisladora dentro do ser humano exerce sobre sua capacidade de agir de acordo com sua vontade, é denominado sentimento moral, um sentido especial (sensus moralis), por assim dizer. [MS, AA VI, 387:05-18 (p. 231), grifo nosso].

Por essas palavras, Kant parece reverberar o exposto no texto de 1784: o Esclarecimento implica uma tarefa moral irrenunciável que comporta, seja o desenvolvimento "instrucional" individual, seja o aprimoramento da vontade, conduzida no rumo de uma boa vontade (gute Wille) ${ }^{9}$. Aqui estariam, no

\footnotetext{
${ }^{8}$ Concorda com essa tese a defesa de Santos, para quem "o que sobressai [...] [na] definição kantiana [de Aufklärung] e a demarca de outras contemporâneas é, para além do registo biológico em que se exprime, o seu vincado acento ético. Exigência da liberdade de pensamento, crítica das instituiçóes (política e religiáo), tudo isso compóe a constelação do conceito. Mas o que é decisivo, o que constitui para Kant a significativa proposta da Aufklärung é o facto de ela representar um imperativo de maioridade da razão, um estado em que, por uma decisão sua, a razão se emancipa das tutelas políticas, religiosas e filosóficas e assume a total responsabilização por si própria." (SANTOS, 1994, p. 144145). Ao assumir esta tese, Santos acaba por conceder que a filosofia crítica em geral é, no limite, uma filosofia interessada em uma "razão eticamente responsabilizada", que, por uma "questão de caráter" e, portanto, ética (SANTOS, 1994, p. 146), não é nada mais que a resposta a "um imperativo de dignidade, de honestidade e de veracidade para com a razáo comum e a humanidade" (SANTOS, 1994, p. 146). Ver ainda Ginzo (1986, p. 204ss).

${ }^{9} \mathrm{Na}$ Fundamentação I, Kant advertira que a vontade boa é a única coisa irrestritamente boa, e boa em si mesma [GMS, AA IV, 393:05-07; 394:13-16 (p. 101; 105)].
} 
entanto, duas finalidades distintas e incompatíveis ou duas faces do mesmo desenvolvimento? A meu ver, a chave de leitura que nos permite resolver o embaraço pode ser encontrada nas discussóes sobre o tema da educação em Kant, o que nos conduz à próxima seção.

\section{Educaçáo e Esclarecimento}

Quando se trata do tema da educação, em Kant, geralmente o público volta a atenção para o pequeno ensaio Sobre a pedagogia [Immanuel Kant über die Pädagogik $\left(1803^{10}\right)$ ]. De antemão, porém, um primeiro problema a respeito do texto em questão ganha destaque: pode-se aceitá-lo como um escrito autêntico de Kant? Fontanella sugere que o texto foi publicado por um discípulo de Kant, Theodor Rink, pelo que se tornou presente no Tomo IX da edição da Real Academia Prussiana de Ciências das Obras completas de Kant (1923); defende ainda que o texto seria resultado de uma prática comum entre os professores da Universidade de Königsberg de se revezarem em curso sobre pedagogia aos discentes, de modo que esse escrito corresponderia a tal curso, para o qual Kant teria composto um texto ligeiro, conciso e não detalhado (FONTANELLA, 1999, p. 5). A edição francesa das obras de Kant sobre o tema da Educação ${ }^{11}$, apresentada por Maalouf nos Annales de philosophie et des sciences humaines, traz ainda a informação de que ali estariam condensados, na verdade, os elementos fundamentais dos quatro cursos sobre a educaçáo proferidos por Kant, entre 1776 e 1787 (MAALOUF, 2004, p. 21-22), que Louden, mais especificamente, diz terem ocorrido no inverno de 1766-1777, no verão de 1780, no inverno de 1783-1784 e no inverno de 1786-1787 (LOUDEN, 2000, p. 33-34).

O debate é ampliado por Ginzo, sobretudo quando recupera a posição de Weisskopf [com base no livro Immanuel Kant und die Pädagogik (1970)], para quem a obra Päd náo pode ser tomada como texto autêntico de Kant (GINZO, 1986, p. 202), embora Barata-Moura ressalte que as referidas liçóes sobre a pedagogia editadas por Theodor Rink teriam sido revistas pelo próprio Kant, antes de sua publicação, em 1803 (BARATA-MOURA, 2007, p. 21).

Como quer que seja - e a despeito das disputas teóricas sobre a problemática da autoria ou pseudoautoria da obra, para o que vale um estudo à parte -, o texto Päd possui uma articulação indiscutível com outros temas e escritos

\footnotetext{
${ }^{10}$ Sobre a datação do texto, cf. Fontanella (1999, p. 5).

${ }^{11}$ A edição em questão é KANT, I. Réflexions sur l'éducation. Tradução francesa de Alexis Philonenko. Paris: Vrin, 1996.
} 
de Kant que abordam, de alguma maneira, a questão pedagógica, tais como os opúsculos sobre a história [particularmente os presentes nos Abhandlungen nach 1781 (AA VIII)], a Antropologia de um ponto de vista pragmático [Anthropologie in pragmatischer Hinsicht (1798)], as Reflexóes de antropologia [um dos volumes das Reflexion, precisamente o nomeado por Anthropologie (Refl, AA $\mathrm{XV})$ ], sem esquecer as três grandes críticas e os escritos sobre filosofia moral e, talvez por isso, Ginzo argumente que, embora Weisskopf levante questionamentos sobre a relevância do texto, seria preciso reconhecer ali observaçóes importantes para a problemática educativa, tratada por Kant (GINZO, 1986, p. 202); essa tese é, de certa forma, também admitida por Beck, quando, ao comentar a obra de Weisskopf, afirma: "Parece-me, no entanto, que Weisskopf provou demais para o seu próprio propósito. Na verdade, ele mostrou motivos muito bons para levar Über die Pädagogik [sic] a sério." (BECK apud LOUDEN, 2000, p. 35, tradução nossa).

De fato, o texto objeto das disputas teóricas rapidamente mencionadas é extremamente provocativo e traz contribuiçôes significativas para pensar a educação, dentro de uma perspectiva integral de indivíduo, de modo que ali estariam contidas não apenas a crença em uma antropologia específica de partida, mas também em uma meta fundamental para o ser humano, para a qual o problema do Esclarecimento parece ser central, o que acaba por acentuar o papel de certo iluminismo para a compreensão do tema da educação, em Kant (em decorrência da conexáo possível entre este e outros textos reconhecidamente escritos por ele). Para confirmar essa tese, Ginzo sustenta que

a preocupação kantiana pela educação e a pedagogia transborda claramente os limites do pequeno ensaio [Sobre a pedagogia] [...]. Para fazer-se uma ideia cabal acerca desse problema, é preciso consultar [...] os escritos kantianos acerca da filosofia da história, da antropologia, da moral, da religião..., assim como as metodologias das três críticas. Só assim podemos ter em conta a relevância e a seriedade que Kant atribuiu ao fenômeno educativo. Aparece, dessa forma, uma conexão profunda entre o pensamento kantiano e o problema da educação, como algo mais profundo e relevante do que cabia suspeitar à primeira vista. (GINZO, 1986, p. 202, tradução nossa).

Daí que o período da Ilustração tenha se dedicado sobremaneira ao problema da educação, pensando-a "tanto desde um ponto de vista teórico como prático” (GINZO, 1986, p. 203, tradução nossa). 
Para mais, é importante ter em conta que a proposta pedagógica de Kant poderia ser compreendida de modo mais adequado, por um lado, com base na compreensão da influência inconteste do Emílio rousseauniano - embora essa influência também tenha alcançado outras vias pelas quais se debruça o pensamento kantiano, tais como sua filosofia da história e a antropologia, e o interesse de Kant pelo tema da educação pareça ser anterior ao seu contato com Rousseau (GINZO, 1986, p. 208) - e, por outro lado, pelo ímpeto reformador dos chamados "filantropistas" da Prússia de sua época. Sobre o último aspecto, é importante considerar que

as idéias inovadoras de Rousseau exerceram uma grande influência sobre a pedagogia do Iluminismo em toda a Europa, que dificilmente pode ser sobreestimado, e tiveram, especialmente, repercussōes frutíferas na Alemanha, isto é, nos Estados do Antigo Império, como mostra a reação de Immanuel Kant. Os pedagogos reformadores na Alemanha do último terço do século XVIII foram, na maioria, professores que derivaram as suas idéias diretamente da prática escolar; o mérito deles consistia, por isso, como Horst Möller (1986, p.135) formula, "na prática refletida". Estes professores leram assiduamente Rousseau, reconhecido por eles como modelo e autoridade também para os seus próprios esforços pedagógicos. Formou-se um grupo de educadores engajados, unido por relaçóes soltas e através de um diálogo permanente com a sociedade erudita do Iluminismo. Incentivados pelo ímpeto do Esclarecimento, eles contribuíram para estabelecer a pedagogia como disciplina independente, livre da tutela eclesiástico-religiosa tradicional. Imitando Rousseau ou, melhor dizendo, o educador do Emílio, começou a formar-se a profissão dos professores que receberam, a partir daí, "uma função-chave própria na preparação e introdução dos adolescentes à vida” (HERRMANN, 1979, p. 137). Os teóricos e práticos da educação, na época do Iluminismo, logo foram denominados, na Alemanha, filantropistas - especialmente segundo o "filantropino", uma escola, fundada em 1774 por Johann Bernhard Basedow (1724-1790) na cidade de Dessau, que se tornou a "escola exemplar dos filantropistas". (MAINKA, 2005, p. 171).

Maalouf ainda lembra que "Kant, desde suas primeiras liçôes [ou cursos sobre o tema da educação], se serviu do Methodenbuch de Basedow e do manual de educação de Samuel Bock" (MAALOUF, 2004, p. 22, tradução nossa), de modo que sua opção hermenêutica também vincula o tratamento do problema da educação ao filantropismo mencionado por Mainka ${ }^{12}$. De

\footnotetext{
${ }^{12}$ Para um aprofundamento da questáo, é importante considerar as contribuiçōes de Mainka (2005), Maalouf (2004) e Ginzo (1986), pois a temática, por si só, já constituiria objeto para uma exposição específica.
} 
qualquer forma é relevante considerar que a concepção kantiana da educação parece passar pelo ambiente dado em seu momento histórico, o qual é "um dos momentos de maior sensibilidade histórica ante ao fenômeno da educação" (GINZO, 1986, p. 201, tradução nossa), e "uma época fascinada pelo problema educativo, uma época em que, como escreveria o pedagogo bávaro J. M. Sailer, poucos anos depois da morte de Kant: 'Nas famílias, nas reunióes de sociedade e nas aulas, a educação era a palavra-chave.." (GINZO, 1986, p. 202-203, tradução nossa).

Iniciada por uma afirmação crucial para perceber a educação como um problema filosófico, Päd começa pela tese de que "o homem é a única criatura que precisa ser educada. Por educação entende-se o cuidado de sua infância (a conservação, o trato), a disciplina e a instrução com a formaçáo." [Päd, AA IX, 441:01-03 (p. 11)]. Isso significa que, analiticamente, temos: (i) que o homem é criatura que tem necessidade da educação; logo, a educação não é acidental e recusável, mas fundamental e irrenunciável; (ii) que a educação é compreendida em sentido lato, uma vez que envolve não só a dimensão de cuidado e da disciplina, mas também a instrução com a formação, o que tornaria o processo educacional algo a ser desenvolvido em etapas - por isso "o homem é infante, educando e discípulo" [Päd, AA IX, 441:04 (p. 11)].

Nessa perspectiva, a necessidade que o homem tem da educaçáo é proporcional àquela que tem de sua própria razão, uma vez que o seu instinto não se equipara ao dos animais, no que tange ao desenvolvimento de sua conduta como ser humano. Kant parte da pressuposição de que o homem nasce em uma espécie de "estado bruto", do qual precisa se desvencilhar, no sentido de levar a efeito uma espécie de destinação: a humanidade não é, pois, algo dado definitivamente em decorrência do simples nascimento, mas algo adquirido, um processo contínuo de conquista de si mesmo do indivíduo. Daí Päd assumir que "a espécie humana é obrigada a extrair de si mesma pouco a pouco, com suas próprias forças, todas as qualidades naturais, que pertencem à humanidade" [Päd, AA IX, 441:24-25 (p. 12)], algo que justificaria uma aproximação entre teleologias: a antropológica, a educacional, a política e, igualmente, a da própria história. Para usar as palavras de Santos,

a filosofia moral, a filosofia política e a filosofia da história kantianas convergem para a educaçáo, entendida num sentido amplo, ou seja, simultaneamente como educação do indivíduo e, segundo expressáo de Lessing, como "educação do gênero humano". Nisso, cumpria Kant, à sua maneira, o projecto da Aufklärung, profundamente marcado por um impulso pedagógico. (SANTOS, 1994, p. 178). 
Um dos dispositivos de que a educação se serve para auxiliar o homem no processo de desenvolvimento de si, no rumo da humanização, é aquele da disciplina, visto que ela "transforma a animalidade em humanidade" [Päd, AA IX, 441:24-25 (p. 12)]. Não nos enganemos: trata-se aqui menos de fomentar uma educação para a subserviência absoluta do sujeito em relação aos outros que para a liberdade, na medida em que a disciplina é tida como aquilo "que impede o homem de se desviar do seu destino, de se desviar da humanidade" [Päd, AA IX, 442:03-04 (p. 12)]. Assim, Kant procura desenvolver sua ideia de educação amparado fundamentalmente na premissa antropológica de que há disposiçôes naturais ínsitas ao ser humano que devem ser aprimoradas, as quais se revelam como disposição técnica, disposição pragmática e disposição moral, e compóem um repertório que tornam o homem distinto de todos os outros habitantes da terra, conduzindo-o na direção da humanidade [Anth, AA VII, 322:13ss (p. 216ss)].

Se o destino do homem é a humanidade e se o interesse da razão repousa fundamentalmente naquilo que é prático, isso significa que (i) a humanidade é uma conquista do homem; e (ii) a destinação moral é o cumprimento final das disposiçóes humanas. Ora, sobre a moral de Kant, os leitores da GMS reconhecem bem a sua tese básica: a boa vontade é a que realiza os imperativos emanados pela razão, em detrimento daqueles gerados pelas inclinaçóes, proporcionando o alcance da autonomia como princípio supremo da moralidade [GMS, AA IV, 440:14ss (p. 285ss)]. O homem é senhor de si mesmo, quando prefere o que é moralmente correto, na medida em que isso só lhe está disponível na obediência ao comando categórico que sua própria razão legisladora oferece: aqui, o homem é autônomo e pode se experimentar como alguém livre, já que a liberdade expressa na obediência à lei moral é recíproca à autonomia. ${ }^{13}$

A pedagogia kantiana assume a tese de que "o homem não pode se tornar um verdadeiro homem senão pela educação. Ele é aquilo que a educação dele faz" [Päd, AA IX, 443:19-20 (p. 15)], e o que se segue daqui é curioso:

\footnotetext{
${ }^{13}$ É o exposto pela "tese da reciprocidade" admitida por Kant, na seção introdutória da terceira transição da GMS [GMS, AA IV, 446s (p. 347ss)], sobre a qual Almeida atesta que "a 'reciprocidade' dos conceitos de uma vontade autônoma e de uma vontade submetida ao princípio moral sugere a Kant a [seguinte] estratégia [...]: provar a liberdade da vontade sem pressupor a validade do princípio moral e recorrer à tese da reciprocidade dos conceitos de autonomia e moralidade para derivar a validade do princípio moral." (ALMEIDA, 2009, p. 37). Para um aprofundamento da questão, cf. Allison (1986, p. 393-425).
} 
ao tempo em que "a educação ensina alguma coisa aos homens [...], [também] não faz mais que desenvolver nele certas qualidades" [Päd, AA IX, 443:2527 (p.15)]. Trata-se de uma perspectiva tipicamente iluminista, embora não descuide dos entraves próprios da natureza humana [Päd, AA IX, 444ss (p. $15 \mathrm{ss})$ ]. No final das contas, a pedagogia kantiana, quando é marcada pelo ideal iluminista, acaba por ceder a uma aposta: a de que o homem pode tornar-se homem, ao tornar-se melhor do que é ${ }^{14}$, seja do ponto de vista cognitivo, seja do ponto de vista moral, porque, longe de se excluírem, os dois domínios constituem duas faces da mesma razão, a qual encontra na realidade concreta as condições para o seu desenvolvimento. É um ideal que conta com a historicidade da razão, embora compreenda que a história é um horizonte aberto. Isso significa, no limite, que o ser humano é, ele mesmo, um projeto em construção permanente, nunca dado definitivamente.

Assim como comparece em seus textos políticos, talvez seja esse o motivo que conduza Kant a reconhecer que "a educação [...] é o maior e mais árduo problema que pode ser proposto aos homens" [Päd, AA IX, 446:17-18 (p. 20)] e que, por isso mesmo, deve ser tomada como um ideal, desde que se compreenda por ideia "o conceito de uma perfeição que ainda não se encontra na experiência ${ }^{15 ”}$ [Päd, AA IX, 444:32-33 (p. 17), grifo nosso], que, portanto, parece assumir uma função eminentemente regulativa. Aqui novamente Kant recupera a conceituação já antes desenvolvida na $\mathrm{KrV}$, na qual a noção de ideia não comporta nenhuma correspondência a qualquer objeto empírico, o que

\footnotetext{
${ }^{14}$ Daí ser importante a consideração de Mainka, para quem "os representantes da pedagogia esclarecida na Alemanha [que influenciaram sobejamente a concepção pedagógica de Kant], desde o início, sempre tiveram a consciência da dimensão política e social da educação. Segundo Ulrich Herrmann (1979, p.154 ss.), a característica fundamental da pedagogia esclarecida na Alemanha, especialmente nos filantropistas, consiste na tentativa [...] de criar, através de novas formas e conteúdos da educação doméstica e escolar, através de instrução e formação, um 'novo homem', o cidadão esclarecido-racional, industrioso-assíduo [industriös-fleißig], orientado pelo bem comum. [...] Uma prova da fé otimista no aperfeiçoamento e, com isso, na moralização do homem através de desdobramento e desenvolvimento profissional de seus talentos, capacidades e disposiçôes, o próprio Kant dá, de maneira impressionante." (MAINKA, 2005, p. 173).

${ }^{15} \mathrm{Em}$ manuscrito provavelmente redigido na década de 1760, mais especificamente entre 1764 e 1770 , Kant anota que "a ideia é um conhecimento a priori (do entendimento) mediante o qual o objeto se torna possível. Ela se refere ao objetivamente prático enquanto principium. Em certo sentido, contém a maior perfeição. Um crescimento só é possível de acordo com uma ideia. No caso dos homens, esta está simplesmente no entendimento e nos conceitos. O sensível é apenas a imagem, p. ex., a ideia contém todas as finalidades no caso da multidão. O esboço é apenas o sensível que está de acordo com a ideia. Toda moralidade se funda em ideias, cuja imagem nos homens é sempre imperfeita. [...] Os ideais [...] são fiç̧ôes que se dão unicamente no caso dos homens e nele. É uma fantasia que tem como finalidade pôr in concreto uma ideia na contemplação." [Refl., AA 19:107-108 (p. 48), tradução nossa].
} 
inviabiliza a possibilidade de ser conhecida pela razão humana, mas que para ela serve de princípio lógico que lhe satisfaça o desejo pelo incondicionado. Nas palavras da primeira Crítica:

O princípio da razão é, pois, na verdade, tão-só uma regra que impóe uma regressão na série de condiçôes de fenômenos dados, à qual não é permitido deter-se num absolutamente incondicionado. Não é, assim, um princípio da possibilidade da experiência e do conhecimento empírico dos objetos dos sentidos e, por conseguinte, não é um princípio do entendimento, porque toda a experiência está encerrada em seus limites (de acordo com a intuição dada); não é também um princípio constitutivo da razão, servindo para ampliar o conceito do mundo sensível para além de toda a experiência possível, mas um princípio que permite prosseguir e alargar a experiência o mais possível e segundo o qual nenhum limite empírico deverá considerarse com o valor de limite absoluto; é, portanto, um princípio da razão que postula, como regra, o que devemos fazer na regressão, mas não antecipa o que é dado em si no objeto antes de qualquer regressão. Por isso lhe chamo princípio regulador da razão. [KrV, A509, B537 (p. 448)].

É importante destacar ainda que, "embora tenhamos de dizer dos conceitos transcendentais da razão que são apenas ideias, nem por isso os devemos considerar supérfluos e vãos" [ $\mathrm{KrV}, \mathrm{A} 329, \mathrm{~B} 385$ (p. 318)], uma vez que dão a unidade necessária de todos os fins possíveis: trata-se precisamente de seu fim no uso especulativo da razão. Por isso, Kant diz que há um uso prático do entendimento, no qual se trata meramente de uma execução conforme regras. Nesse caso, a ideia da razão prática sempre pode ser real, ainda que dada só parcialmente in concreto. Por esse motivo,

a idéia prática é, pois, sempre altamente fecunda e incontestavelmente necessária em relação às ações reais. A razão pura tem nela a causalidade necessária para produzir, efetivamente, o que o seu conceito contém: pelo que se não pode dizer da sabedoria, de certo modo displicentemente, que é apenas uma idéia; mas, justamente, por ser a idéia da unidade necessária de todos os fins possíveis, deverá servir de regra para toda a prática, como condição originária, ou, pelo menos, limitativa. $[\mathrm{KrV}$, A328, B385 (p. 318)].

A proposta educacional de Kant, quando concebida a partir de um ideal da razão, compreende-se como ideia de uma perfeição a ser buscada, no sentido de que ela deve orientar a prática efetiva dos indivíduos que devem tomar a seu encargo a tarefa de promovê-la, na realidade histórica concreta. 
Por esse motivo, esse ideal da razão, que se compromete com o aperfeiçoamento permanente do indivíduo - porque, no limite, o problema da educação equivale ao problema do aprimoramento humano na direção de sua perfeição como homem - não pode se esquivar do problema da autonomização do sujeito, da formação do indivíduo, no sentido de o incentivar à vivência da sabedoria verdadeira: a educação, afinal, deve cuidar da promoção do "lema do Esclarecimento", do "sapere aude?" ou, o que é o mesmo, do "aprender a pensar por si mesmo", de sua "autonomização".

\section{EdUCAÇÁo E FILOSOFIA: A QUESTÁO dA AUTONOMIA E DO MELHORAMENTO HU- MANO EM UM HORIZONTE POLÍTICO}

Nessa perspectiva, à educação cabe uma responsabilidade bastante grave: a de tornar homem o homem. Isso significa que, no problema da educação, esconde-se o problema fundamental da existência humana, o qual envolve a tematização da perfeição da natureza humana. Se é assim, então não é possível pensar o problema pedagógico como um mero apêndice, muito menos como uma questão a ser resolvida pela simples transmissão de informaçóes. Trata-se de abordar o destino humano que, a juízo de Kant, está ancorado num melhoramento permanente do indivíduo e de suas relaçóes com outros indivíduos, uma vez que o fim humano é tornar-se moral, o que significa aceitar (i) em primeiro lugar, que o homem deve atuar, no sentido de aprimorar sua relação concreta com o ambiente em que está encerrado e com as pessoas com as quais convive, como indivíduo "terrestre" - é nesse sentido, me parece, que vai a apresentação de Kant a respeito da promoção da felicidade alheia como "fim que é também um dever" [MS, AA VI, 387-388:24-35;01-30 (p. 231-232)] e, (ii) em segundo lugar, que o homem é também convocado a lutar pelo estabelecimento de um mundo moral, o qual, afinal, se opóe a qualquer modo de vida degradante para outros homens, cada vez mais próximo do "ideal" a que sua razão o impele a concretizar, ainda que isso não lhe seja possível de completar sozinho, em razão de sua ocorrência orgânica finita. ${ }^{16}$ Conforme Kant,

\footnotetext{
${ }^{16}$ Como propõe, em IaG, "no homem (única criatura racional sobre a Terra) aquelas disposiçôes naturais que estão voltadas para o uso de sua razão devem desenvolver-se completamente apenas na espécie e não no indivíduo. [...] se a natureza concedeu-lhe somente um curto tempo de vida (como efetivamente aconteceu), ela necessita de uma série talvez indefinida de geraçóes que transmitam umas às outras as suas luzes para finalmente conduzir, em nossa espécie, o germe da natureza àquele grau de desenvolvimento que é completamente adequado ao seu propósito. Eeste momento precisa ser, ao menos da ideia dos homens, o objetivo de seus esforços, pois senão as disposiçōes naturais em grande parte teriam de
} 
o homem há de se ver destinado a dois mundos inteiramente distintos; em primeiro lugar, para o mundo dos sentidos e do entendimento, quer dizer, para este mundo terrestre; mas também para outro mundo que nos é desconhecido, o reino da moralidade. [...] Essa moralidade, e não o entendimento, é o rasgo distintivo primordial que converte o homem em um ser humano. [SF, AA VII, 70. 72:19-22;34-35 (p. 50; 52), tradução nossa].

De qualquer modo, ao tomar o fim último (Endzweck) do ser humano e deixá-lo a cargo da educação, salientando que o próprio ser humano é o "fim último (Endzweck) da criação" [cf. KU, AA VII, \$ 84, 434ss (p. 283ss)], Kant contribui para pensá-la para além da mera transmissão de conhecimentos e, por isso, sugere que a educação seja uma espécie de "arte", para a qual o mecanicismo não é apenas insuficiente, senão prejudicial [Päd, AA IX, 447:01-03 (p. 22)]. Daí o papel do professor ser compreendido mais acima do mero repasse de informaçóes; na verdade,

de um professor espera-se que, nos seus ouvintes, forme, primeiramente, o homem que entende, depois o que raciocina e, finalmente, o sábio. [...] ele não deve aprender pensamentos, mas aprender a pensar, não se deve levá-lo, mas guiá-lo, se se pretende que no futuro ele seja capaz de caminhar por si mesmo. [NEV, AA II, 305-306:23-25;23-25 (p. 189)].

O que se depreende da passagem é que Kant considera o professor como uma espécie de tutela passageira, por meio da qual o estudante adquire as ferramentas para já não mais precisar dele, pois estaria adquirindo os instrumentos para alcançar sua autonomia. Por esse motivo, compreende a dificuldade inevitável de se lidar, na educação, com o adolescente, porque ele "estava habituado a aprender. Agora ele pensa que vai aprender filosofia, o que é, porém, impossível, porque agora ele tem de aprender a filosofar" [NEV, AA II, 306:29-32 (p. 190)], mas sobreleva a função do professor como "filósofo prático" - ou o "verdadeiro filósofo" -, compreendido como "mestre da sabedoria", que ensina "através da doutrina e do exemplo" [Log, AA IX, 24:16 (p. 41)].

Note-se que, no limite, o que Kant pretende instigar é o desenvolvimento de uma postura ativa do indivíduo (algo que se justifica a partir de sua conhecida "reviravolta copernicana", desde a Crítica de 1781), uma atitude

ser vistas como inúteis e sem finalidade - o que aboliria todos os princípios práticos." [IaG, AA VIII, 1819:29-34;01-13 (p. 5-6), grifo nosso]. 
crítica diante do que o cerca, na medida em que isso corresponde ao aprimoramento humano, o que significa admitir um duplo efeito a ser conquistado também pela educação, a saber, (i) a autonomização do indivíduo singular, mas também, no limite, (ii) o melhoramento do gênero humano como um todo. Daí que seria possível qualificar a ideia de educação para Kant como uma "pedagogia da humanidade na qual o bem geral (Weltbeste) e o bem privado (Privatbeste) poderiam conciliar-se harmonicamente" (GINZO, 1986, p. 222 , traduçáo nossa). Como o homem convive com outros iguais a si, parece legítimo que o resultado de uma educação comprometida seja necessariamente um impacto político de transformaçáo da realidade para tornar nela exequível o aperfeiçoamento permanente do ser humano. Isso, no entanto, já é uma crítica ao próprio contexto histórico de Kant, na medida em que

a idéia de aperfeiçoamento de cada um dos homens e a sua utilização para o bem público e o bem estar de todos, assim como a idéia que resulta disso, a saber, a idéia de um melhoramento progressivo das condiçóes estatais, econômicas e sociais através da educação abalaram, conseqüente e inevitavelmente, a ordem social tradicional, sustentada em classes diferenciadas por nascimento. A valorizaçáo crescente de capacidades, conhecimentos e trabalhos [Leistung] individuais que resultou necessariamente numa mobilidade social, entrou, evidentemente, sempre mais em conflito com a realidade política e social. Enquanto essas tensões eclodiram na França com violência na Grande Revoluçáo de 1789, elas se tornaram imanentes no sistema do Absolutismo Esclarecido, ou seja, do Absolutismo Reformista [Reformabsolutismus] e resultaram, no fim do século XVIII, em paralisação e estagnação, sem causar uma mudança política radical. (MAINKA, 2005, p. 174).

Ao que parece, portanto, Kant estaria interessado em discutir o papel que a educação pode desempenhar no desenvolvimento da intervenção política dos indivíduos, ao instigar a reflexão sobre a autonomia e a luta pelo bem comum (beneficência), mas também sobre a importância da erudiçáo, da tolerância e da paz, e o afastamento de condutas prejudiciais à dignidade humana (não-maleficência $)^{17}$, pois, se é verdade que "mediante a arte e a ciência, somos

\footnotetext{
${ }^{17}$ Daí Kant insistir, já em 1795, na proposta de uma Confederação de Estados ou de uma política voltada para o cosmopolitismo, do que se segue a advertência para a inviabilidade moral da existência de um exército permanente para os Estados particulares, já que "ser contratado para matar ou para ser morto parece envolver um uso de seres humanos como simples máquinas e ferramentas nas mãos de outro (um Estado), e isso não pode ser conciliado com o direito da humanidade em nossa própria pessoa" [ZeF, AA VIII, 345:07-11 (p. 318), tradução nossa], embora Kant reconheça que a não-maleficência é reconhecida como dever mais propriamente pelo homem moralizado, uma vez que
} 
cultivados em alto grau" e "somos civilizados até a saturação por toda espécie de boas maneiras e decoros sociais [...], ainda falta muito para nos considerarmos moralizados" [IaG, AA VIII, 26:20-23 (p. 16)], o que significa assumir a educação como um ideal aberto porque o próprio homem é um projeto inacabado. O próprio "kantismo [...] é o modelo exemplar de uma filosofia do inacabamento" (LACROIX, 1988, p. 117).

Para compreender de maneira mais comprometida a questão, é importante tomar ainda em consideração a dupla compreensão de Kant a respeito do conceito de filosofia ${ }^{18}$, a saber, (i) como "conceito escolástico" e (ii) como "conceito cósmico". Sobre (i), Kant assume a filosofia como "o sistema dos conhecimentos filosóficos ou dos conhecimentos racionais a partir de conceitos" [Log, AA IX, 23:30-31 (p. 41)], o qual tem a peculiaridade de desenvolver a habilidade que aspira a um saber especulativo e faz do filósofo um "artista da razão", cujo escopo é eminentemente teórico e concede um tratamento sistemático ao objeto de sua reflexão; quanto a (ii), a filosofia é compreendida como a "ciência dos fins últimos da razão humana" [Log, AA IX, 23:32-33 (p. 41)], a qual permitiria o desenvolvimento de uma utilidade positiva, posto que tornaria o filósofo um "legislador", um "mestre da sabedoria pela doutrina e pelo exemplo" e o faria capaz de lidar com os fins últimos da razão humana [Log, AA IX, 24:17-19 (p. 41)], o que possibilita o alcance da plenitude da filosofia e compreende seu interesse como eminentemente prático.

Tomada nos sentidos referidos, a filosofia aparece, então, como atividade que possui um papel análogo aos objetivos da educação, porque

a um filósofo incumbem sobretudo duas coisas: 1) a cultura do talento e da habilidade, para empregá-los em vista de toda espécie de fins. 2) A destreza no emprego de todos os fins para qualquer fins. As duas coisas têm que estar reunidas; pois, sem conhecimentos, jamais alguém há de se tornar filósofo, mas jamais tampouco os conhecimentos hão de fazer o filósofo, enquanto a isso não se vier juntar de modo a constituir uma unidade uma ligaçáo funcional de todos os conhecimentos e habilidades e um discernimento da concordância dos mesmos com os fins mais elevados da razão humana. Ninguém que não possa filosofar pode chamar-se

a "facilidade em fazer guerra [... ] parece estar implantada na natureza humana" [ZeF, AA VIII, 345:3436 (p. 319), tradução nossa].

${ }^{18}$ Mesmo que, segundo Barata-Moura, “a pergunta 'que é filosofia?' não recebe um tratamento sistemático que permita elucidar toda a riqueza do seu conteúdo ou o alcance total das suas implicaçôes. Todavia, a filosofia como tal, isto é, a filosofia em acto, está inegavelmente presente ao longo da obra de Kant. É ela que a anima e lhe fornece a matéria sobre a qual se debruça. [...] A filosofia para Kant não é tanto objecto de exposição, mas objecto de preocupação." (BARATA-MOURA, 2007, p. 27, 29). 
filósofo. Mas filosofar é algo que só se pode aprender pelo exercício e o uso próprio da razáo. [...] $\mathrm{O}$ verdadeiro filósofo, portanto, na qualidade de quem pensa por si mesmo, tem que fazer um uso livre e pessoal de sua razão, não um uso servilmente imitativo. [Log, AA IX, 25-26:18-29;09-11 (p. 42-43), grifo nosso].

Nesse contexto, Kant identifica a atividade de pensar por si mesmo ao ato de filosofar. Se a educação deve tomar como pressuposto a necessidade de instigar o pensamento livre, esclarecido, bem como a formação moral que torne o indivíduo capaz náo apenas de saber teoricamente sobre o bem, mas de ser moralmente melhor, por conseguinte, a educação deve formar para a sabedoria, para a filosofia compreendida em seu sentido cósmico, tendo em conta que "a sabedoria tem como finalidade somente o bom, a perfeição" [Refl, AA XIX, 109:10 (p. 48), tradução nossa]. Deve-se estimular a superação do saber teórico e dirigir-se ao saber prático, visto que o "pensar por si mesmo" equivale ao "pensar criticamente".

Se se toma por pressuposto a vinculação conceitual entre a filosofia e a autonomia que deve ser propugnada pela educação, a compreensão da pedagogia ganha ainda melhores contornos, porque, em sua Lógica [Immanuel Kants Logik ein Handbuch zu Vorlesungen (1800)], Kant reserva um espaço importante para tematizar o problema da distinção do conhecimento (i) quanto à sua origem objetiva e (ii) quanto à sua origem subjetiva [Log, AA IX, 22:11-20 (p. 39)]. Quando fala da (i) origem objetiva, Kant argumenta que o conhecimento se divide em racional ou empírico, ou seja, ou o conhecimento seria originário da razão ou dos sentidos; sobre (ii), argumenta que o conhecimento pode ser racional ou histórico, para dizer que ou o sujeito que o apreende o faz por uma criação de sua razão inventiva ou o sujeito o assimila imitativamente. Essa distinção é relevante para Kant, na medida em que compreende que a filosofia náo se ensina como um mero conhecimento histórico, mas exige um esforço ativo do educando, para empreender o ato de filosofar. Assim compreendido, o filosofar é o propósito da educação, para o que o subjetivo uso mecânico da razão não é o suficiente, pois exige um seu uso livre, criador [Log, AA IX, 22:29-32 (p. 40)], o que atinge o universo teórico como o prático, posto que

a filosofia só atinge plenamente a sua essência quando transcende um nível meramente técnico-instrumental para alcançar o âmbito do fundamento. A "utilidade" significa um misto de capacidade-habilidade e de utilização que possibilita um emprego dos conteúdos da filosofia como que desligados, 
do plano radical das "finalidades últimas da razão humana". Ao definir-se como doutrina da sabedoria, em contrapartida, a filosofia está a realizar a articulação suprema com a temática do homem e dos seus fins. (BARATAMOURA, 2000, p. 65, nota 27).

Em NEV, Kant transparece a ideia de que havia certo "ordenamento escolástico" da educação em sua época, o qual acabava preocupado unicamente em infundir informaçóes no estudante, desconsiderando o seu desenvolvimento biológico-intelectivo ou a maturidade do educando ${ }^{19}$ [NEV, AA II, 305:01ss (p. 188)]. Daí Kant postular a importância de se "respeitar o gradual desenvolvimento do intelecto", de tal maneira que, do ponto de vista metodológico, "a educação deve ser uma coisa gradual e os graus de educação devem ser estruturados de tal modo a respeitar e facilitar os graus sucessivos do natural processo físico da consciência” (SBRIZ, 2003, p. 26, tradução nossa). Esse método, antes de mais, teria "a vantagem de que o aprendiz, mesmo que jamais chegue ao último grau, como em geral acontece, terá sempre ganhado alguma coisa com o ensino e se terá tornado mais exercitado e mais atinado, senão perante a escola, pelo menos perante a vida" [NEV, AA II, 305-306:2526;01-02 (p. 173)], o que significa que o método, uma vez aplicado, auxilia o estudante a pensar por si mesmo. Ao que parece, esse aspecto procedimental do tema da educação em Kant é absolutamente compatível com o processo descrito em Päd, que começa com a disciplina, passa pelo cultivo de si, pela aquisição da civilidade/prudência e culmina na busca permanente de seu aprimoramento moral [Päd, AA IX, 449-450:27-37;01-14 (p. 25-26)].

Nesse sentido, ao ensinar a pensar por si ou a filosofar, o método kantiano parece querer apontar para o fato de que o educando, munido dessa ferramenta, teria condiçôes de se dirigir no rumo da liberdade, da autonomia, daquela que é a destinação final do ser humano. No limite, a proposta de autonomização do sujeito acaba por coincidir com aquele ideal do Esclarecimento e com a conquista de sua humanização. Um indivíduo moralizado, que passou por todas as "etapas" da educação, no entanto, entende como sua a tarefa de promover o melhoramento da humanidade no convívio com outros homens,

\footnotetext{
${ }^{19}$ Sbriz, a esse respeito, comenta: "pense-se, por exemplo, o fato de que se entrava na Faculdade filosófica aos dezesseis anos: apenas em 1810 será teorizada, com W. von Humboldt, uma mudança do ensino da filosofia, tendo em conta o método de aquisição dos conteúdos; segundo von Humboldt, de fato, o verdadeiro fim do homem é a formação máxima proporcionada pelas suas forças como um todo: a partir dessa convicção, ele aprofundou a sua ideia de uma Universidade livre, ou seja, não-estatal, e finalizada [na ideia de] formaçáo global do homem, segundo um critério que respeitasse a liberdade de ensino e de pesquisa." (SBRIZ, 2003, p. 26, tradução nossa).
} 
na medida em que, conforme Kant, "constitui um dever para consigo mesmo, bem como para com os outros, não se isolar (separatistam agere), mas usar as próprias perfeições morais na convivência social (officium commercii, sociabilitas)" [MS, AA VI, 473:16-18 (p. 316)]. O argumento parece servir de justificação moral para permanência do homem em associação com outros iguais, embora Kant aceite a tese da "insociável sociabilidade", pela qual sustenta que

o homem tem uma inclinação para se associar porque se sente mais como homem num tal estado, pelo desenvolvimento de suas disposiçóes naturais. Mas ele também tem uma forte tendência a separar-se (isolar-se), porque encontra em si ao mesmo tempo uma qualidade insociável que o leva a querer conduzir tudo simplesmente em seu proveito, esperando oposição de todos os lados, do mesmo modo que sabe que está inclinado a, de sua parte, fazer oposição aos outros [IaG, AA VIII, 20-21:34-35;01-15 (p. 8)],

pois que a associação ou a união civil entre os homens corresponde à maior de todas as suas necessidades [IaG, AA VIII, 22:05ss (p. 10)]..$^{20}$

A consequência disso é que o progresso na direção da moralização parece conduzir o indivíduo, ao mesmo tempo, à busca pela promoção de um mundo moral, o que o faz estar atento aos deveres que possui para com a humanidade, entre os quais aquele de se envolver na propagação de um projeto pedagógico que insista no desenvolvimento integral do indivíduo, a fim de torná-lo cada vez mais moralizado. Daí que a educação seja compreendida por Kant como

uma arte, cuja prática necessita ser aperfeiçoada por várias geraçóes. Cada geração, de posse dos conhecimentos das gerações precedentes, está sempre melhor aparelhada para exercer uma educaçáo que desenvolva todas as disposiçôes naturais na justa proporção e de conformidade com a finalidade daquelas e, assim, guie toda a espécie humana a seu destino. [Päd, AA IX, 446:01-06 (p. 19)].

No limite, o compromisso do homem moralizado com a educação é similar ao compromisso que, por uma força interna, sente possuir com a humanidade também do ponto de vista político, na medida em que entende a necessidade de se alcançar a fundação de uma "constituição civil perfeitamente justa" [IaG, AA VIII, 22:18, (p. 10)], tarefa táo difícil quando a de educar [Päd, AA IX, 446:29-31 (p. 20)]. Por esse motivo, o tema da educaçáo, em

${ }^{20}$ Para um aprofundamento da discussão, cf. Schneewind (2009) e Wood (2009). 
Kant, permanece vinculado igualmente ao problema do melhoramento político, a um ideal de emancipação real do ser humano, pois a educaçáo, compreendida para além da instrução escolar, como formação integral, "o prepara para tornar-se um cidadão, uma vez que lhe confere um valor público [...]. A formação moral lhe dá um valor que diz respeito à inteira espécie humana." ${ }^{21}$ [Päd, AA IX, 455:17-22 (p. 35)].

LIMA FILHO, J. E. Enlightenment and education in Kant: autonomy as a human development project. Trans/form/ação, Marília, v. 42, n. 2, p. 59-84, Abr./Jun., 2019.

ABstract: Based on the thought of Immanuel Kant (1724-1804), this article argues that education and human development are notions that necessarily involve one another. From a Kantian position, one cannot conceive a pedagogical proposal whose goal does not end up as the self-construction of the rational theoretical-practical subject. Based on a reading of the opera kantiana, we start from the

${ }^{21}$ A questáo fica ainda mais evidente quando, em um breve registro a respeito do número XII da Gothaische gelehrte Zeitungen de 1784, Kant comenta que, se a humanidade é teleologicamente orientada ao desenvolvimento de todas as suas disposiçóes naturais - o que deve ocorrer no gênero e não no indivíduo singular - também é o caso que, nos humanos, "a razão [...] necessit[e] de tentativas, exercícios e ensinamentos para progredir, aos poucos, de um grau de inteligência (Einsicht) a outro" [IaG, AA VIII, 18-19:32;01-03 (p. 5-6), grifo nosso], o que implica (i) que o ser humano precisa da educação, do ponto de vista da orientação de sua razão e (ii) que ele tem, de fato, um compromisso moral com a melhoria do mundo para as próximas geraçôes, o que deve mover seus esforços [IaG, AA VIII, 19:07ss (p. 6)] e justificar seu trabalho, haja vista aquela tendência natural do homem a se associar com outros homens [IaG, AA VIII, 20-21:25ss (p. 8-9)]. Daí que Kant dedique uma nota importante à função "humanizadora" do trabalho, algo que, em geral, é descuidado nas leituras mais apressadas sobre sua filosofia, quando reconhecem esse traço apenas no pensamento de Hegel e Marx. Na verdade, porém, quando se refere ao trabalho, Kant defende que a atividade laboral é o instrumento que eleva o indivíduo "da máxima rudeza à máxima destreza e à perfeição interna do modo de pensar" [IaG, AA VIII, 20:02-04 (p. 7)] e que, por isso, a educação também deve cuidar de, desde cedo, estimular o educando ao trabalho: "a criança deve brincar, ter suas horas de recreio, mas deve também aprender a trabalhar. Certamente é bom exercitar a sua habilidade e cultivar o seu espírito; mas deve-se dedicar horários diferentes a estas duas espécies de cultura. Constitui grande infelicidade para o homem ter de ficar à toa tão frequentemente. Quanto mais ele se abandona à preguiça, mais dificilmente se decide a trabalhar. [...] É de suma importância que as crianças aprendam a trabalhar. O homem é o único animal obrigado a trabalhar. Para que possa ter o seu sustento, muitas coisas deve fazer necessariamente para tal. [...] o homem precisa de ocupaçóes, inclusive daquelas que implicam certo constrangimento. [...] O homem deve permanecer ocupado, de tal forma que, tendo em vista o fim que almeja, realize-se sem sentir-se a si mesmo, e que o seu melhor repouso seja aquele que sucede ao trabalho. Que a criança, portanto, seja habituada ao trabalho. E onde a tendência ao trabalho pode ser mais bem cultivada que na escola?" [Päd, AA IX, 470-472:21-27;06-21;01 (p. 60-62)]. 
necessity of the unity of reason and present arguments that seek to justify the notion of pedagogy as the fulfillment of the ideal of the modern Enlightenment, which has at its core the development of the individual from both the moral and theoretical-speculative point of view. Altogether, the idea of education coincides with the proposal of the Enlightenment, which, for its part, is nothing more than that of the self-construction of the subject as the master of him or herself and as an open horizon in permanent improvement.

KeYwords: Education. Human development. Enlightenment.

\section{REFERÊNCIAS}

ALLISON, H. E. Morality and freedom: Kant's reciprocity thesis. The Philosophical Review, v. XCV, p. 393-425, 1986.

ALMEIDA, G. A. Introdução. In: KANT, I. Fundamentação da metafísica dos costumes. Tradução de Guido Antônio de Almeida. São Paulo: Discurso Editorial \& Barcarolla 2009. (Coleção Philosophia).

BARATA-MOURA, J. Kant e o conceito de filosofia: com um texto em apresentação bilingue extraído da "Lógica". Braga: Centro de Filosofia da Universidade de Lisboa, 2007.

FONTANELLA, F. C. Prefácio. In: KANT, I. Sobre a pedagogia. Tradução de Francisco Cock Fontanella. Piracicaba: Editora UNIMEP, 1999. p. 11-36.

GUINZO, A. La filosofía de la educaciónen Kant. Revista de Filosofía. Santiago, 2. s., n. IX, p. 201-232, 1986.

KANT, I. Akademieausgabe von Immanuel Kants Gesammelten Werken. Bände und Verknüpfungen zu den Inhaltsverzeichnissen. Versão digital. Disponível em: https:// korpora.zim.uni-duisburg-essen.de/Kant/verzeichnisse-gesamt.html. Acesso em: 15 mar. 2018.

(Algumas traduçôes comentadas das obras de Kant, bem como outras edições, foram indicadas aqui como alternativas de consulta utilizadas para a construção deste texto, dentre outras consultadas, quais sejam)

KANT, I. Resposta à pergunta: que é "Esclarecimento"? In: Textos seletos. Tradução de Floriano de Sousa Fernandes. Petrópolis: Vozes, 1985. p. 100-117.

. Lógica. Traduçáo de Guido Antônio de Almeida. Rio de Janeiro: Tempo Brasileiro, 1992.

. Informação acerca da orientação dos seus Cursos no Semestre de Inverno de 1765-1766. In: SANTOS, L. R. A razão sensivel: estudos kantianos. Lisboa: Colibri, 1994. p. 188-191.

. Réflexions sur l'éducation. Tradução de Alexis Philonenko. Paris: Vrin, 1996a. 
. Toward perpetual peace. In: Practical philosophy. Tradução de Mary J.

Gregor. Cambridge: Cambridge University Press, 1996b. p. 311-351.

- La contienda entre las facultades de filosofía y teología. Tradução de Roberto Rodríguez Aramayo. Madrid: Trotta, 1999a.

. Sobre a pedagogia. Tradução de Francisco Cock Fontanella. Piracicaba: Editora UNIMEP, 1999b.

. A metafísica dos costumes. Tradução de Edson Bini. Bauru: EDIPRO, 2003a.

Ideia de uma história universal de um ponto de vista cosmopolita. Tradução de Rodrigo Naves e Ricardo R. Terra. São Paulo: Martins Fontes, 2003 b.

. Reflexiones sobre filosofía moral. Tradução de José G. Santos Herceg. Salamanca: Sígueme, 2004.

. Fundamentação da metafísica dos costumes. Tradução de Guido Antônio de Almeida. São Paulo: Discurso Editorial \& Barcarolla, 2009a.

. Idea for a Universal History with a Cosmopolitan Aim. In: RORTY, A. O.;

SCHMIDT, J. Kant's idea for a universal history with a cosmopolitan aim: a critical guide. Cambridge: Cambridge University Press, 2009b. p. 9-23.

. Crítica da faculdade do juizo. Tradução de Valerio Rohden e António Marques.

Rio de Janeiro: Forense Universitária, 2010a.

- Crítica da razão pura. Tradução de Manuela Pinto dos Santos e Alexandre

Fradique Morujão. Lisboa: Fundação Calouste Gulbenkian, 2010b.

LACROIX, J. Kant e o kantismo. Porto: Rés, 1988.

LOUDEN, R. Kant's impure ethics: from rational beings to human beings. New York;

Oxford: Oxford University Press, 2000.

MAALOUF, J. Présentation de "réflexions sur l'éducation" d'Emmanuel Kant. Annales de Philosophie et des Sciences Humaines, n. 18, p. 21-36, 2004.

MAINKA, P. J. A política educacional do estado prussiano na época de Kant e as tendências pedagógicas do período. Quesito: Revista de Estudos em Educação, Sorocaba, v. 7, n. 2, p. 167-183, 2005.

MORUJÃO, A. F. Prefácio da tradução portuguesa. In: KANT, I. Crítica da razão pura. Tradução de Manuela Pinto dos Santos e Alexandre Fradique Morujão. Lisboa: Fundaçáo Calouste Gulbenkian, 2010. p. V-XXVI.

SANTOS, L. R. A razão sensivel: estudos kantianos. Lisboa: Colibri, 1994.

SBRIZ, S. Kant e la comunicazione didattica della filosofia. Comunicazione Filosofica, Roma, n. 11, p. 21-49, out. 2003. 
SCHNEEWIND, J. B. Good out of evil: Kant and the idea of unsocial sociability. In: RORTY, A. O.; SCHMIDT, J. Kant's idea for a universal history with a cosmopolitan aim: a critical guide. Cambridge: Cambridge University Press, 2009. p. 94-111.

WOOD, A. Kant's fourth proposition: the unsociable sociability of human nature. In: RORTY, A. O.; SCHMIDT, J. Kant's idea for a universal history with a cosmopolitan aim. A Critical Guide. Cambridge: Cambridge University Press, 2009. p. 112-128.

\section{Siglas das obras de Kant utilizadas (Akademie Ausgabe)}

\begin{tabular}{l|l} 
AA & Akademie Ausgabe \\
\hline Anth & Anthropologie in pragmatischer Hinsicht (AA 07) \\
\hline GMS & Grundlegung zur Metaphysik der Sitten (AA 04) \\
\hline IaG & $\begin{array}{l}\text { Idee zu einer allgemeinen Geschichte in weltbürgerlicher Absicht } \\
\text { (AA 08) }\end{array}$ \\
\hline KrV & $\begin{array}{l}\text { Kritik der reinen Vernunft (zu zitieren nach Originalpaginierung } \\
\text { A/B) }\end{array}$ \\
\hline KU & Kritik der Urteilskraft (AA 05) \\
\hline Log & Logik (AA 09) \\
\hline MS & Die Metaphysik der Sitten (AA 06) \\
\hline NEV & $\begin{array}{l}\text { Nachricht von der Einrichtung seiner Vorlesungen in dem } \\
\text { Winterhalbenjahre von 1765-1766 (AA 02) }\end{array}$ \\
\hline Päd & Pädagogik (AA 09) \\
\hline Refl & Reflexion (AA 14-19) \\
\hline SF & Der Streit der Fakultäten (AA 07) \\
\hline WA & Beantwortung der Frage: Was ist Aufklärung? (AA 08) \\
\hline ZeF & Zum ewigen Frieden (AA 08) \\
\hline
\end{tabular}

Recebido: 02/09/2017

Aceito: 28/08/2018 
LIMA FILHO, J. E. 